\title{
The difficulties of ambulatory interscalene and intra-articular infusions for rotator cuff surgery: a preliminary report
}

\author{
[Difficultés des perfusions interscalènes et intra-articulaires ambulatoires pour la \\ réparation de la coiffe des rotateurs : un rapport préliminaire]
}

Stephen M. Klein MD, ${ }^{*}$ Susan M. Steele MD, ${ }^{*}$ Karen C. Nielsen MD, ${ }^{*}$ Ricardo Pietrobon MD, $\dagger$ David S. Warner MD,${ }^{*}$ Aliki Martin RN,${ }^{*}$ Roy A. Greengrass MD FRCP*

Purpose: Rotator cuff repair may result in severe postoperative pain. We compared a continuous intra-articular infusion to a continuous interscalene block with ropivacaine for patients undergoing outpatient rotator cuff repair.

Methods: Seventeen patients were randomized to one of two groups: I) interscalene block with $0.5 \%$ ropivacaine $(40 \mathrm{~mL})$ followed by a postoperative intra-articular infusion or; 2 ) interscalene block with $0.5 \%$ ropivacaine $(40 \mathrm{~mL})$ followed by a postoperative continuous interscalene infusion. Infusions were $0.2 \%$ ropivacaine at $10 \mathrm{~mL} \cdot \mathrm{hr}^{-1}$ for both groups. Infusions were maintained for $48 \mathrm{hr}$. Patients were discharged on the day of surgery. Verbal analogue pain scores (VAS) and postoperative oxycodone consumption were measured for $48 \mathrm{hr}$.

Results: Eight patients (47\%; four in each group) had side effects or logistical problems complicating care. The mean VAS scores at rest and with movement in the postanesthesia care unit and at 12 $\mathrm{hr}, 24 \mathrm{hr}$, and $48 \mathrm{hr}$ were not different $(P>0.1)$. Inadequate analgesia was reported in $50-75 \%$ of all study patients. Time until first oxycodone use was similar between groups $829 \mathrm{~min} \pm 432$ (interscalene) and $999 \mathrm{~min} \pm 823$ (intra-articular; $P=0.6$ ). Total oxycodone consumption was also similar $49 \mathrm{mg} \pm 48$ and $59 \mathrm{mg} \pm$ 5I $(P=0.7)$, respectively.

Conclusions: This study demonstrates the difficulties of ambulatory interscalene and intra-articular infusion for rotator cuff surgery. The high VAS scores and need for additional medical care suggest that intra-articular administration may not be reasonable for this magnitude of surgery. Further refinement of the perineural local anesthetic infusion is necessary to consistently provide analgesia after ambulatory rotator cuff surgery.
Objectif : La réparation de la coiffe des rotateurs peut provoquer des douleurs postopératoires sévères. Nous avons comparé une perfusion intra-articulaire continue à un bloc interscalène continu avec de la ropivacaïne chez des patients devant subir la réparation de la coiffe des rotateurs en chirurgie ambulatoire.

Méthode : Dix-sept patients ont été répartis au hasard en deux groupes : I) bloc interscalène avec de la ropivacaïne à 0,5\% (40 mL) suivi d'une perfusion intra-articulaire postopératoire ou 2) bloc interscalène avec de la ropivacaïne à 0,5\% (40 mL) suivi d'une perfusion postopératoire interscalène continue. Les perfusions comportaient de la ropivacaïne à 0,2\% administrée selon $10 \mathrm{~mL} \cdot \mathrm{hr}^{-1}$ dans les deux groupes. Elles ont été maintenues pendant $48 \mathrm{~h}$. Les patients ont reçu leur congé le jour de l'intervention. Les scores verbaux de l'échelle visuelle analogique (EVA) et la consommation d'oxycodone postopératoire ont été notés pendant $48 \mathrm{~h}$.

Résultats : Huit patients (47\%; quatre dans chaque groupe) ont été traités pour des effets secondaires ou des complications de problèmes logistiques. Les scores moyens à l'EVA enregistrés au repos et en mouvement n'ont pas été différents après l'anesthésie ou 12, 24 et 48 h plus tard $(P>0,1)$. Une analgésie incomplète a été rapportée chez 50-75\% de tous les patients de l'étude. Le temps écoulé avant la première demande d'oxycodone a été similaire dans les deux groupes : $829 \mathrm{~min}$ \pm 432 (interscalène) et $999 \min \pm 823$ (intra-articulaire ; $P=0,6$ ). La consommation totale d'oxycodone aussi a été semblable : $49 \mathrm{mg} \pm$ 48 et $59 \mathrm{mg} \pm 51(P=0,7)$.

Conclusion : L'étude démontre les difficultés d'une perfusion ambulatoire interscalène ou intra- articulaire en chirurgie de la coiffe des rotateurs. Les scores élevés de l'EVA et les besoins de soins supplémentaires supposent que l'administration intra-articulaire ne soit pas appropriée à l'importance de l'intervention chirurgicale. II faut raffiner la perfusion périneurale d'anesthésique local afin de fournir une analgésie constante après l'opération ambulatoire de la coiffe des rotateurs.

From the Departments of Anesthesiology, ${ }^{*}$ and Surgery, $†$ Duke University Medical Center, Durham, North Carolina, USA.

Address correspondence to: Dr. Stephen M. Klein, Box 3094, Department of Anesthesiology, Duke University Medical Center, Durham,

North Carolina 27710, USA. Phone: 919-668-2056; Fax: 919-668-2081; E-mail: Klein006@mcis.duke.edu

Sponsorship: Departmental. Pumps were supplied by Sorrensen Medical, West Jordan, UT, USA

Accepted for publication July 29, 2002.

Revision accepted November 11, 2002. 


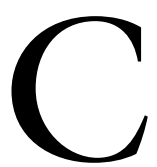

ONTINUOUS local anesthetic via an intraarticular or interscalene brachial plexus infusion has been advocated to reduce postoperative pain after rotator cuff repair. Data comparing these two routes are unavailable. Furthermore, despite the efficacy of these techniques on inpatients and after minor surgery, information examining the feasibility and logistics of this practice on outpatients is needed. We compared continuous infusion of $0.2 \%$ ropivacaine at $10 \mathrm{~mL} \cdot \mathrm{hr}^{-1}$ via the intra-articular or interscalene brachial plexus routes in patients undergoing outpatient rotator cuff repair.

\section{Methods}

The Institutional Review Board approved this study and informed patient consent was obtained. Patients scheduled for open rotator cuff repair classified as ASA physical status I-III, aged 18 yr or older, participated in this study. Patient exclusion criteria included chronic opioid use, morbid obesity or contraindications to regional anesthesia.

All patients received an interscalene brachial plexus block as their primary anesthetic. Patients were randomized to one of two groups: 1) intra-articular group (CIA; $n=8$ ): postoperative intra-articular infusion; 2 ) interscalene group (CISB; $n=9$ ): postoperative continuous interscalene infusion.

Using the approach previously described by Winnie, ${ }^{1}$ single injection blocks were placed using a $50-\mathrm{mm}$ insulated, blunt needle and a nerve stimulator. The CISB group had their blocks placed using the same technique but with the Contiplex Insulated Tuohy System ${ }^{\circledR}$ (B. Braun Medical, Bethlehem, PA, USA). After finding a distal motor response at $<0.5$ $\mathrm{mA}, 40 \mathrm{~mL}$ of $0.5 \%$ ropivacaine with epinephrine $1: 400,000$ was injected. The CISB group also had a 20 -gauge catheter inserted $(<10 \mathrm{~cm})$. After negative aspiration of the catheter, a $3-\mathrm{mL}$ test dose was given.

With evidence of a successful motor block, patients underwent rotator cuff repair. Sedation was provided with iv propofol $10-50 \mu \mathrm{g} \cdot \mathrm{kg}^{-1} \cdot \mathrm{min}^{-1}$. Ketorolac $30 \mathrm{mg}$ $i v$ was administered at the end of surgery. Patients randomized to receive a CIA infusion had the same catheter inserted $10 \mathrm{~cm}$ via an arthroscopy portal into the joint.

On arrival to the postanesthesia care unit (PACU), either the CIA or CISB catheter was attached to a disposable infusion pump (Microjet ${ }^{\circledR}$, Sorrensen Medical, West Jordan, UT, USA) containing $480 \mathrm{~mL}$ of $0.2 \%$ ropivacaine and infused at $10 \mathrm{~mL} \cdot \mathrm{hr}^{-1}$ for $48 \mathrm{hr}$. Patients were prescribed oral naproxen $500 \mathrm{mg}$ or celecoxib 100 $\mathrm{mg}$ twice daily for four days and acetaminophen 325 $\mathrm{mg}$ with oxycodone $5 \mathrm{mg}$ to take if necessary.
Prior to discharge, patients were given verbal and written instructions concerning catheter care, signs and symptoms of local anesthetic toxicity and how to contact study personnel. Patients were required to have an adult with them for the duration of the infusion. Twice daily telephone calls were made by a trained nurse to answer questions and query about problems. When patients met standard PACU criteria they were discharged home.

Patients were asked to rate their pain at rest and while ambulating during activities of daily living using a verbal analogue pain scale (VAS; $0 \mathrm{~cm}=$ no pain $/ 10$ $\mathrm{cm}=$ worst pain imaginable) on arrival in PACU, and then at $12 \mathrm{hr}, 24 \mathrm{hr}$ and $48 \mathrm{hr}$ postsurgery. Patients also documented the consumption of oral analgesics and the time of consumption.

Data are presented as mean \pm standard deviation. Means were compared using the test for normally distributed variables or the Wilcoxon rank-sum test for non-normal variables. Proportions were compared using the chi-square or the Fisher exact tests. All tests were two-tailed with a significance set at 0.05 .

\section{Results}

Seventeen patients were enrolled $(\mathrm{CISB}=9 ; \mathrm{CIA}=8$ ). We anticipated enrolling 20 patients per group but because of pain complaints, side effects and protocol violations we performed an interim analysis to determine if these problems were isolated to one group. Given the results of the interim analysis the trial was stopped. There were no significant differences in age, weight, gender or ASA classification between CISB/CIA groups.

Eight patients $(47 \%)$ had side effects or logistical problems complicating care. One CISB catheter was removed prematurely at $29 \mathrm{hr}$, because the patient was pain free and believed that the catheter was no longer necessary. A second CISB patient had the catheter removed at $24 \mathrm{hr}$ because the family became anxious about the risks of continuing the infusion. A third CISB patient developed severe pain (VAS 8) at $12 \mathrm{hr}$ and returned at $24 \mathrm{hr}$ for treatment of nausea. This was attributed to consumption of oxycodone and pain. One CIA patient had the surgical dressing reinforced multiple times because of saturation from the infusion. Another CIA patient had severe pain at $24 \mathrm{hr}$ requiring iv opioids. This patient's intra-articular catheter required a surgeon to manipulate the arm for removal. A third CIA patient complained of dizziness and elected to remove the catheter at $24 \mathrm{hr}$. A fourth CIA patient developed severe pain (VAS rest $=10)$ at $12 \mathrm{hr}$ leading to an emergency department admission. These seven patients had their data included in all subsequent 


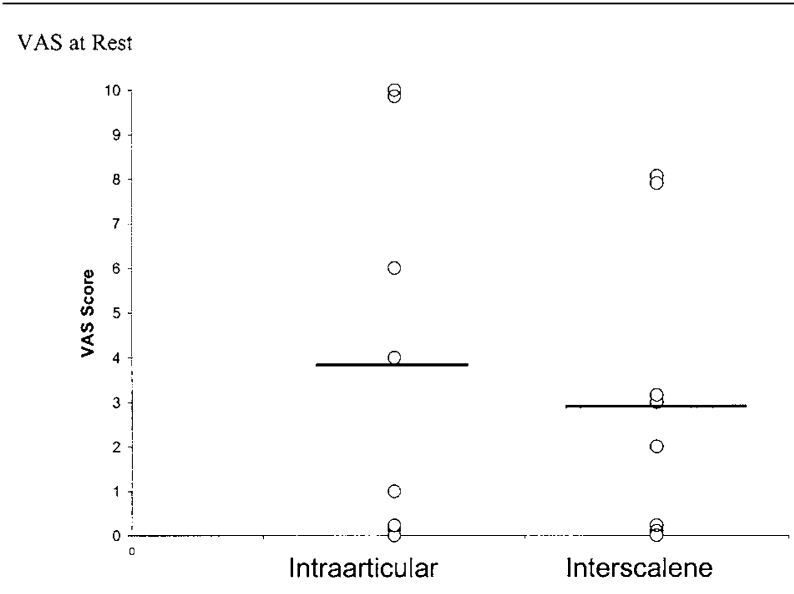

VAS with Ambulation

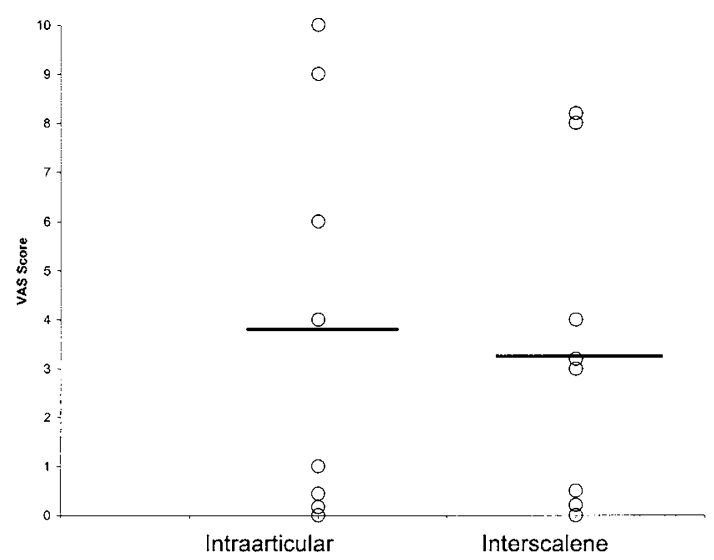

FIGURE 1 Verbal analogue pain scores (VAS; $0=$ no pain $/ 10=$ worst pain imaginable) after $12 \mathrm{hr}$ at rest and with ambulation. Intra-articular $=$ continuous intra-articular local anesthetic infusion; Interscalene $=$ continuous interscalene local anesthetic infusion. Horizontal bars indicate mean values.

analysis according to an intention-to-treat analysis protocol. One CISB patient was judged unable to follow instructions and dropped from data analysis.

The VAS scores for both groups on arrival to PACU at rest were $0 \pm 0$. The VAS scores with ambulation were $0 \pm 0$ for the CISB group and $1.25 \pm 3.55$ for the CIA group $(P=0.3)$. The VAS scores at rest and with movement were also not different at $12 \mathrm{hr}, 24 \mathrm{hr}$, and $48 \mathrm{hr}(P>0.1$; Figures 1 to 3$)$. Inadequate analgesia (VAS $>2$ ) was high in both groups at these times. Overall, between $50 \%$ and $71 \%$ of all patients reported suboptimal analgesia. Pain scores were consistently lower for patients in the CISB group, although the difference was not statistically significant. Time until first

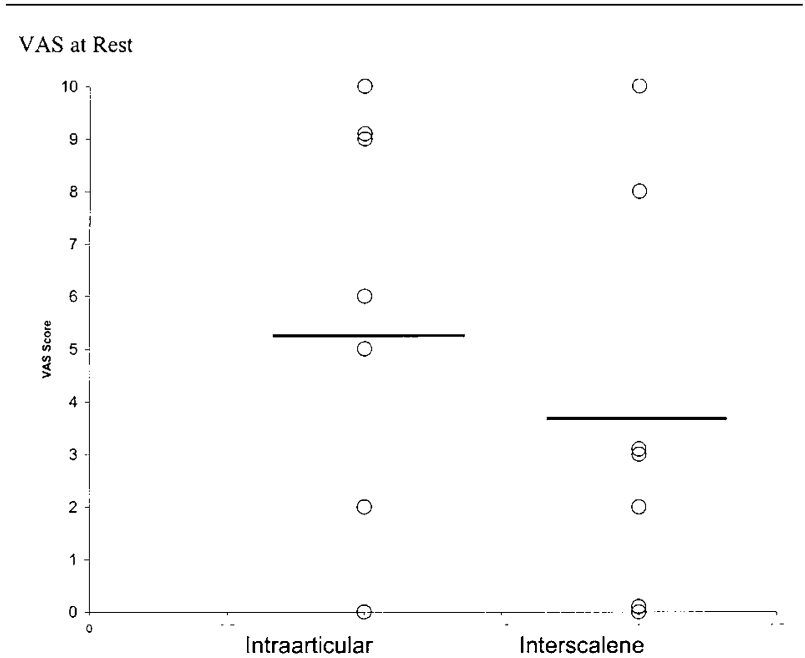

VAS with Ambulation

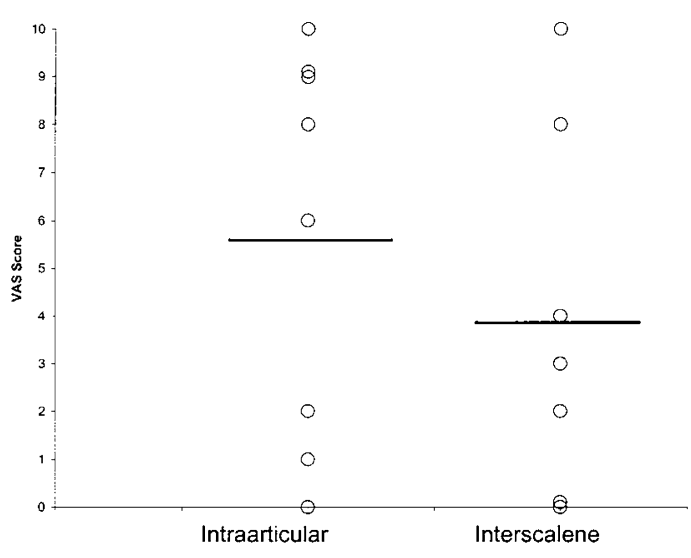

FIGURE 2 Verbal analogue pain scores (VAS; $0=$ no pain $/ 10=$ worst pain imaginable) after $24 \mathrm{hr}$ at rest and with ambulation. Intra-articular = continuous intra-articular local anesthetic infusion; Interscalene $=$ continuous interscalene local anesthetic infusion. Horizontal bars indicate mean values.

oxycodone use was similar between groups: $829 \mathrm{~min} \pm$ 432 (CISB) and $999 \mathrm{~min} \pm 823$ (CIA) $P=0.6$. Total oxycodone consumption was also similar. (CISB $=49$ $\mathrm{mg} \pm 48 ; \mathrm{CIA}=59 \mathrm{mg} \pm 5 \mathrm{l} ; P=0.7$.

\section{Discussion}

The study demonstrates the difficulty of successfully using continuous interscalene or intra-articular infusions of local anesthetic for rotator cuff surgery outside of the hospital. Patients in both groups (52\%-71\%) experienced intense pain after resolution of their initial surgical block. Despite continuous local 


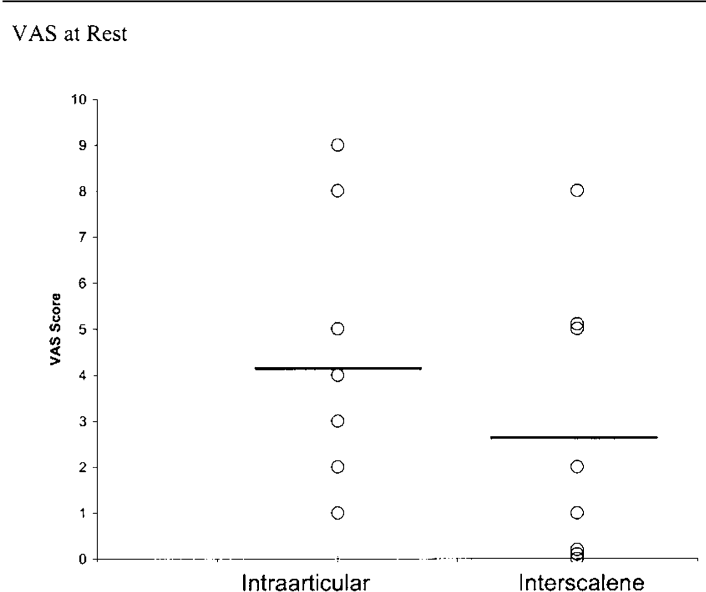

VAS with Ambulation

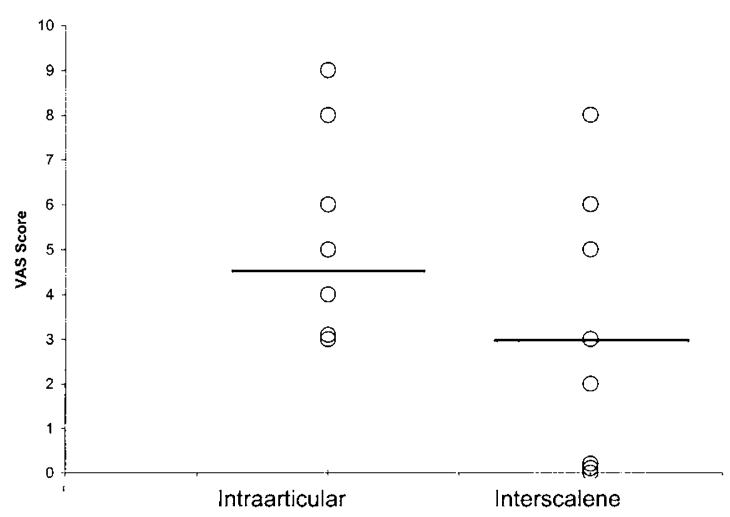

FIGURE 3 Verbal analogue pain scores (VAS; $0=$ no pain $/ 10=$ worst pain imaginable) after $48 \mathrm{hr}$ at rest and with ambulation. Intra-articular = continuous intra-articular local anesthetic infusion; Interscalene $=$ continuous interscalene local anesthetic infusion. Horizontal bars indicate mean values.

anesthetic infusion, neither group was consistently able to achieve satisfactory analgesia (VAS $<2$ ) with supplemental oxycodone. In addition, logistical barriers remain to achieve ideal results.

Despite recent case series, no prospective data are available comparing outpatient continuous interscalene infusions with conventional analgesic choices. In our previous study ${ }^{2}$ excellent pain control was achieved in patients receiving $0.2 \%$ ropivacaine at $10 \mathrm{~mL} \cdot \mathrm{hr}^{-1}$. Failure to achieve these results with the current study design may be attributable to several factors.

Patients were instructed to take oxycodone after they developed pain as opposed to during block resolution. This slow-onset, weak opioid was insufficient to deal with the sudden development of pain from a previously analgesic site. Further, although our previous study ${ }^{3}$ demonstrated encouraging results with intra-articular ropivacaine for shoulder arthroscopy, the current patient population underwent rotator cuff repair. The poor pain control observed may be attributable to larger incisions and to local anesthetic leaking through the wound. Finally, another factor in the CISB group may have been inaccurate catheter placement. Because blocks were dosed via the needle and then the catheter was inserted, correct placement was not assured. We believe this was unlikely based on prior work. ${ }^{4}$

This study also presented logistical difficulties. Many patients expected to be admitted to the hospital after surgery of this magnitude and were hesitant to participate. In addition, because many patients developed pain at home (50-71\%) they frequently expressed displeasure with their analgesia and complained to their surgeon. This, combined with the frequent protocol violations, caused us to stop the study.

Despite the difficulties with this study design, previous work ${ }^{2,5-8}$ suggests that perineural infusions have the potential to provide improved analgesia after outpatient shoulder surgery. The ability to rapidly reinforce the block with a local anesthetic bolus would likely improve results. ${ }^{6}$ Additional instruction about the transition period from surgical anesthesia to postoperative analgesia may also be necessary. This protocol could also be improved with the prophylactic administration of an opioid after eight to ten hours or the use of an extended release opioid. Finally, continuous infusion of local anesthetic via the intra-articular route may be insufficient for this magnitude of surgery.

\section{References}

1 Winnie AP. Interscalene brachial plexus block. Anesth Analg 1970; 49: 455-66.

2 Klein SM, Grant SA, Greengrass RA, et al. Interscalene brachial plexus block with a continuous catheter insertion system and a disposable infusion pump. Anesth Analg 2000; 91: 1473-8.

3 Klein SM, Nielsen KC, Martin A, et al. Interscalene brachial plexus block with continuous intraarticular infusion of ropivacaine. Anesth Analg 2001; 93: 601-5.

4 Grant SA, Nielsen KC, Greengrass RA, Steele SM, Klein $S M$. Continuous peripheral nerve block for ambulatory surgery. Reg Anesth Pain Med 2001; 26: 209-14.

5 Tuominen M, Haasio J, Hekali R, Rosenberg PH. Continuous interscalene brachial plexus block: clinical efficacy, technical problems and bupivacaine plasma concentrations. Acta Anaesthesiol Scand 1989; 33: $84-8$. 
6 Singelyn FJ, Seguy S, Gouverneur JM. Interscalene brachial plexus analgesia after open shoulder surgery: continuous versus patient-controlled infusion. Anesth Analg 1999; 89: 1216-20.

7 Borgeat A, Tewes E, Biasca N, Gerber C. Patient-controlled interscalene analgesia with ropivacaine after major shoulder surgery: PCIA vs PCA. Br J Anaesth 1998; 81: 603-5.

8 Rawal N, Axelsson K, Hylander J, et al. Postoperative patient-controlled local anesthetic administration at home. Anesth Analg 1998; 86: 86-9. 